\title{
HFOV vs CMV for neonates with moderate-to-severe perinatal onset acute respiratory distress syndrome (NARDS): a propensity score analysis
}

\author{
Kaizhen Liu $^{1} \cdot$ Long Chen $^{1} \cdot$ Jing Xiong ${ }^{1} \cdot$ Shuqin Xie $^{2} \cdot$ Yuan Hu$^{1} \cdot$ Yuan Shi $^{1}$ \\ Received: 22 August 2020 / Revised: 12 January 2021 / Accepted: 15 January 2021 / Published online: 27 February 2021 \\ (C) The Author(s), under exclusive licence to Springer-Verlag GmbH, DE part of Springer Nature 2021
}

\begin{abstract}
This study aimed to evaluate whether high-frequency oscillatory ventilation (HFOV) could reduce mortality and the incidence of bronchopulmonary dysplasia (BPD) of perinatal-onset neonatal acute respiratory distress syndrome (NARDS) compared with conventional mechanical ventilation (CMV). Medical records were collected and retrospectively analyzed. Among the 700 neonates with NARDS who needed invasive ventilation, 501 (71.6\%) received CMV, while 199 (28.4\%) received HFOV. One-to-one propensity score matching (127:127) was used to match the baseline characteristics of patients who received CMV and HFOV. The results showed that birth weight and oxygenation index (OI) were independently associated with mortality in the multivariate logistic regression. No significant differences were observed in mortality or the incidence of BPD between the two groups. The incidence of intraventricular hemorrhage (IVH) and ventilation-free days were significantly lower in the HFOV group than in the CMV group (3.9 vs $11.80 \%, p=0.02 ; 15.226$ vs 20.967 days, $p=0.01$ ). There were no significant differences between the two groups regarding other secondary outcomes.

Conclusion: HFOV was associated with a decreased incidence of IVH in infants with NARDS compared with CMV. However, there were significantly more VFDs in the CMV group than in the HFOV group, and HFOV did not appear to be superior to CMV in decreasing the mortality and incidence of BPD in infants with NARDS.

What is Known:

- The diagnostic criteria of neonatal acute respiratory distress syndrome (Montreux criteria) were established in 2017.

- To date, studies comparing high-frequency oscillatory ventilation and conventional mechanical ventilation in the treatment of neonatal acute respiratory distress syndrome are insufficient.

What is New:

- High-frequency oscillatory ventilation did not appear to be superior to conventional mechanical ventilation in decreasing the mortality and incidence of bronchopulmonary dysplasia in infants with moderate-to-severe perinatal-onset neonatal acute respiratory distress syndrome.

- High-frequency oscillatory ventilation was associated with a decreased incidence of intraventricular hemorrhage in infants with moderate-to-severe perinatal-onset acute respiratory distress syndrome compared with conventional mechanical ventilation.
\end{abstract}

Keywords NARDS $\cdot \mathrm{HFOV} \cdot \mathrm{CMV} \cdot$ Neonates

Communicated by Daniele De Luca

Yuan Shi

shiyuan@hospital.cqmu.edu.cn

Kaizhen Liu

liukaizhen@163.com

Long Chen

476679422@qq.com

Jing Xiong

644017859@qq.com

Shuqin Xie

xieshuqin@hospital.cqmu.edu.cn
1 Department of Neonatology, Children's Hospital of Chongqing Medical University; National Clinical Research Center for Child Health and Disorders; Ministry of Education Key Laboratory of Child Development and Disorders; Chongqing Key Laboratory of Pediatrics, Chongqing, People's Republic of China

2 Department of Nephrology, The Second Affiliated Hospital of Chongqing Medical University, Chongqing, People's Republic of China 


$\begin{array}{ll}\text { Abbreviations } \\ \text { ARDS } & \text { Acute respiratory distress syndrome } \\ \mathrm{BPD} & \text { Bronchopulmonary dysplasia } \\ \mathrm{CMV} & \text { Conventional mechanical ventilation } \\ \mathrm{FiO}_{2} & \text { Fraction of inspired oxygen } \\ \mathrm{HFOV} & \text { High-frequency oscillatory ventilation } \\ \mathrm{IVH} & \text { Intraventricular hemorrhage } \\ \text { IQR } & \text { Interquartile range } \\ \mathrm{MAS} & \text { Meconium aspiration syndrome } \\ \text { NARDS } & \text { Neonatal acute respiratory distress syndrome } \\ \text { NICU } & \text { Neonatal intensive care unit } \\ \text { NEC } & \text { Necrotizing enterocolitis } \\ \text { OI } & \text { Oxygenation index } \\ \text { PPHN } & \text { Persistent pulmonary hypertension of the newborn } \\ \text { PEEP } & \text { Positive end-expiratory pressure } \\ \text { PSM } & \text { Propensity score matching } \\ \text { PDA } & \text { Persistent ductus arteriosus } \\ \text { PROM } & \text { Premature rupture of membranes } \\ \text { PARDS } & \text { Pediatric acute respiratory distress syndrome } \\ \text { PICUs } & \text { Pediatric intensive care units } \\ \text { PVL } & \text { Periventricular leukomalacia } \\ \text { ROP } & \text { Retinopathy of prematurity } \\ \text { RCTs } & \text { Randomized controlled trials } \\ \text { RDS } & \text { Respiratory distress syndrome } \\ \text { VLBW } & \text { Very low birth weight } \\ \text { VG } & \text { Volume-guarantee } \\ \text { VFDs } & \text { Ventilation-free days } \\ & \end{array}$

\section{Introduction}

The diagnostic criteria of acute respiratory distress syndrome (ARDS) in children and adults have been widely recognized, while the diagnostic criteria of neonatal acute respiratory distress syndrome (NARDS) were not developed until 2017 (Montreux criteria) [1]. NARDS is associated with meconium aspiration, sepsis and infectious pneumonia, pulmonary hemorrhage, perinatal asphyxia complicated by severe respiratory failure, and biliary pneumonia according to the Montreux criteria [1]. A study in late preterm and term infants showed that the incidence of ARDS is approximately $28.8 \%$ [2].

Invasive mechanical ventilation, including conventional mechanical ventilation (CMV) and high-frequency oscillatory ventilation (HFOV), is an effective method for the treatment of ARDS in critically ill neonates. With its combined advantages of delivering small tidal volumes with low phasic pressure changes at supraphysiologic frequencies [3], stable/ higher mean airway pressure, and avoiding gas trapping, HFOV may be associated with improved lung protection. In addition, studies of HFOV in children also showed benefits in short-term oxygenation, although no improvement in clinical outcomes was observed [4]. However, the results of some previous human trials comparing the two modes of ventilation remain inconclusive [5].

To date, there are insufficient studies comparing HFOV and CMV in the treatment of NARDS, and the clinical outcomes of CMV and HFOV in the treatment of neonates with respiratory failure are inconsistent; therefore, we conducted this retrospective study to compare the mortality and incidence of bronchopulmonary dysplasia (BPD) between neonates with moderate-to-severe perinatal-onset NARDS who received HFOV and CMV.

\section{Materials and methods}

\section{Patient selection}

This retrospective study was conducted in the Department of Neonatology, Children's Hospital of Chongqing Medical University, China. The data were collected from the medical records of the Department of Neonatology from 1 January 2014 to 31 October 2018. Ultimately, 700 neonates (gestational age of 24 weeks 0 day to 42 weeks 0 days) with perinatalonset moderate-to-severe NARDS who received HFOV or CMV within $24 \mathrm{~h}$ after birth were enrolled.

\section{Inclusion criteria}

For a neonate to be included, the following four criteria had to be fulfilled: (1) gestational age between $24+0$ and $42+0$ weeks; (2) diagnosis of NARDS; and (3) moderate-to-severe NARDS and invasive ventilation within $24 \mathrm{~h}$ after birth.

\section{Exclusion criteria}

Neonates meeting at least one of the following criteria were not eligible for the study: (1) neonates who only needed noninvasive ventilation; (2) neonates with major congenital anomalies or chromosomal abnormalities; (3) neonates with upper respiratory tract abnormalities; (4) neonates with pulmonary adenomatous malformations, sequestration, congenital diaphragmatic hernia, or pulmonary hypoplasia; or (5) neonates with crossover between CMV and HFOV.

\section{Intervention}

Indications of invasive ventilation include respiratory failure (including respiratory acidosis, arterial blood gas $\mathrm{pH}<7.2$ and $\mathrm{PaCO}_{2}>60 \mathrm{mmHg}$; hypoxemia, $\mathrm{PaO}_{2}<50 \mathrm{mmHg}$ under auxiliary oxygen supply or under noninvasive ventilation; fraction of inspired oxygen $\left(\mathrm{FiO}_{2}\right)>40 \%$; severe apnea) [6].

The indications for CMV mechanical ventilation in this study were as follows [7]: (1) $\mathrm{PaO}_{2}<50 \mathrm{mmHg}$, (2) $\mathrm{PaCO}_{2}$ $>60 \mathrm{mmHg}$, (3) intractable or recurrent apnea, (4) gasping or 
poor respiration, (5) $\mathrm{O}_{2}$ saturation $<85 \%$ on supplemental oxygen.

The indications for HFOV mechanical ventilation in this study were as follows [8]: insufficient carbon dioxide elimination, respiratory acidosis (i.e., $\mathrm{pH}<7.20-7.25$ ); and/or hypoxemia $\left(\mathrm{PaO}_{2}<50 \mathrm{mmHg}\right) /$ hypercarbia $\left(\mathrm{PaCO}_{2}>60 \mathrm{mmHg}\right)$; apnea/bradycardia; increasing respiratory distress; high fractional oxygen requirement. HFOV was for primary use not rescue in this study.

\section{Ventilation strategies}

Infants assigned to CMV received ventilation with Servo-i and SLE 5000 ventilators. Conventional ventilation was delivered by time-cycled, pressure-limited ventilators starting with a rate of $30-40$ breaths per minute and an inspiratory time of $0.4 \mathrm{~s}$. The aimed tidal volumes were $4-6 \mathrm{ml} / \mathrm{kg}$, and positive end-expiratory pressure (PEEP) was $5-8 \mathrm{mmHg}$.

Infants assigned to HFOV received ventilation with the SensorMedics 3100A and SLE 5000 ventilators. The open lung strategy was used in this study. There was no crossover to HFOV or CMV in this study. Patients were ventilated with the selected ventilation modes (HFOV or CMV) through the treatment period.

Tube diameters were chosen according to the patient's weight. Ventilator settings were adjusted at the discretion of the attending clinician to maintain arterial oxygen saturation, as measured by pulse oximetry, between 88 and $96 \%$, a $\mathrm{PaO}_{2}$ between 50 and $80 \mathrm{~mm} \mathrm{Hg}$, a $\mathrm{PaCO}_{2}$ between 35 and $55 \mathrm{~mm}$ $\mathrm{Hg}$, and a $\mathrm{pH}$ between 7.20 and 7.45. Analysis of the first blood gas was performed at admission, monitored every 6$18 \mathrm{~h}$ for $24 \mathrm{~h}$, and then monitored daily until the infant was extubated. Chest radiography was performed immediately at admission and was reviewed daily for 2 to 3 days and then once every 5 to 7 days until extubation. Chest ultrasound was performed after admission and was reviewed daily for 2 to 3 days and then once every 5 to 7 days until extubation. Echocardiography was performed within $24 \mathrm{~h}$ after admission. If required, echocardiography was performed again at any time.

Extubation criteria are as follows: $\mathrm{pH}>7.20, \mathrm{PaCO}_{2}<55$ $\mathrm{mmHg}$, Paw $6 \mathrm{cmH}_{2} \mathrm{O} ; \mathrm{FiO}_{2}$ 0.30; sufficient spontaneous breathing effort without any clinical and radiologic sign of respiratory distress, per clinical evaluation [9].

\section{Definition of the important diagnoses and concepts}

The diagnosis of NARDS was made according to the criteria established by the Montreux conference in 2017 [1]: acute onset; oxygenation impairment with reduced end expiratory lung volume requiring positive pressure to recruit the alveoli; respiratory failure not fully explained by lung edema due to heart failure; and diffuse bilateral opacities with loss of aeration on chest radiographs. The following neonatal respiratory disorders qualify for a diagnosis of ARDS: meconium, milk, bile, blood, or water aspiration; lung hemorrhage; and infectious or biliary pneumonia. Acute processes occurring in extrapulmonary organ systems that might trigger acute respiratory failure via systemic inflammatory responses and thus meet ARDS criteria, such as early- or late-onset sepsis, fetal inflammation, perinatal asphyxia, and necrotizing enterocolitis.

Moderate-to-severe perinatal-onset NARDS was determined by the use of the oxygenation index $(\mathrm{OI})$ and triggers, including perinatal asphyxia, early-onset sepsis, and other perinatal factors that occurred in the first $24 \mathrm{~h}$ of life. Severe NARDS was determined by an OI of $\geq 16$, and moderate NARDS was determined by an OI between 8 and 16 [1].

Diagnostic criteria for pneumonia, MAS, and aspiration were according to the references [[1, 10]].

Diagnostic criteria for the following outcomes were according to the literature: bronchopulmonary dysplasia (BPD) [11], retinopathy of prematurity (ROP) [12], NEC [13], intraventricular hemorrhage (IVH) [14], and ventilation-free days (VFDs) [15].

\section{Data collection}

Data collected included demographics (i.e., gestational age, sex, birth weight, age at admission, and age at NARDS diagnosis), perinatal factors (premature rupture of membranes $[\mathrm{PROM}]$ and triggers sepsis, pulmonary hemorrhage, MAS, pneumonia, aspiration of blood, and perinatal asphyxia), elements of NARDS (i.e., disease severity and type of ventilation), 5-min Apgar score, lactate at admission, strategies during hospitalization (i.e., surfactant use), primary outcomes (i.e., death rate and BPD), and secondary outcomes (i.e., IVH $\geq 3$ rd stage, ROP $\geq 2$ nd, NEC $\geq 2$ nd stage, air leak, duration of invasive ventilation, ventilation-free days, and duration of hospitalization).

Data were obtained from the clinical records and were collected daily on web-based case report systems provided by Open CDMS. All data were collected from the electronic medical record.

Primary outcomes were neonatal intensive care unit (NICU) mortality and the incidence of BPD. Secondary outcomes included complications during hospitalization, such as IVH $\geq 3$ rd stage, ROP $\geq 2$ nd stage, NEC $\geq 2$ nd stage, air leakage, duration of invasive ventilation, ventilation-free days, and duration of hospitalization.

\section{Statistical analysis}

All data were analyzed using SPSS 23.0 software (Chicago, IL, USA). The results are presented as the median (interquartile range $[\mathrm{IQR}]$ ) for continuous variables and the number $(\%)$ 
for categorical variables. The normality of the data distribution was tested with the Kolmogorov-Smirnov test. Independent continuous variables were analyzed using $T$ tests, and categorical variables were analyzed using chi-square or Fisher's exact tests. A $p$ value $<0.05$ was considered statistically significant.

Propensity score matching (PSM) was estimated using a logistic regression model in which the following covariates were included: gestational age, sex, birth weight, age at admission, age at NARDS diagnosis, perinatal factors (PROM and triggers sepsis, pulmonary hemorrhage, MAS, pneumonia, aspiration of blood, and perinatal asphyxia), OI, surfactant use, prenatal glucocorticoid, postnatal glucocorticoid, 5-min Apgar score, and lactate at admission. Those covariates were selected based on the previous literature in which an association between those indicators and mortality and the incidence of BPD in adults and PARDS was reported [16-18]. A 1:1 "nearest neighbor" case-control match without replacement was used [19]. Each neonate who received CMV was matched with the neonate who received HFOV and who had the closest estimated propensity scores. Post-match variables were compared between the groups using univariate and multivariate analysis. The variables that were considered to have a univariable association $(p<0.2)$ with mortality were included in multivariate logistic regression analysis to determine the independent factors of mortality $(p<0.05)$. After each step of the multivariate analysis, we evaluated the collinearity by starting with a correlation matrix if the addition of the new variable had a large effect on the point estimate for another parameter in the model. When variables were highly correlated, the variable with the highest univariable association with the outcome in the multivariate analysis was retained. All analyses were verified by three statisticians (LC, JX, and SQX).

\section{Results}

\section{Clinical characteristics of neonates with NARDS}

Between 1 Jan 2014 and 31 Oct 2018, 40,176 infants were admitted to the Department of Neonatology, Children's Hospital of Chongqing Medical University. Among them, 3302 infants suffered from respiratory failure and needed invasive mechanical ventilation, and the total number of infants who needed assisted ventilation, including noninvasive and invasive mechanical ventilation, was 5691. Ultimately, 700 infants met the criteria for entry (199 cases were assigned to HFOV and 501 cases to CMV) (Fig. 1).

The characteristics of the two groups before and after matching are shown in Tables 1 and 2. Before matching, 8 out of the 17 covariates, including sex, age at admission, prenatal glucocorticoid use, postnatal glucocorticoid use, 5-mi
Apgar score, OI, pulmonary hemorrhage, and pneumonia, were significantly different between the two groups. After matching, 254 cases were included in the PSM model. All 17 covariates were well balanced, and no significant differences were observed (Tables 1 and 2).

\section{Mortality and BPD}

Before matching, the overall mortality of neonates with NARDS was $18.5 \%$ (130 of 700), and the incidence of BPD was $19 \%$ (133 of 700). After matching, the mortality of neonates with NARDS was $25.2 \%$ (64 of 254), and the incidence of BPD was $19.2 \%$ (49 of 254). There were no significant differences in mortality or the incidence of BPD between the two groups ( 25.2 [32 of 127] vs $25.2 \%$ [ 32 of 127]; $p=1.000$ and 16.5 [21 of 127] vs $22.0 \%$ [ 28 of 127]; $p=0.266$ ) (Table 3). In particular, the death rate of neonates with severe NARDS was $40.47 \%$ (51/126), while that of neonates with moderate NARDS was $10.23 \%$ (13/127) after matching.

\section{Secondary outcomes}

There were no significant differences between the two groups regarding the other secondary outcomes, including air leakage, ROP, NEC, surfactant treatment, PDA treatment, duration of invasive ventilation, and duration of hospitalization (Table 3). The incidence of IVH ( $\geq 3$ rd stage) was significantly lower in the HFOV group than in the CMV group (3.9 vs $11.8 \%, p=0.020$ ). The VFDs in the CMV group was significantly higher than that in the HFOV group (20.96 vs 15.22 days, $p=0.01$ ).

\section{Univariate and multivariate analyses of neonate mortality at NARDS diagnosis}

Univariate and multivariate analyses were performed to identify the risk factors that were associated with neonate mortality at NARDS diagnosis, and the results are shown in Tables 4 and 5.

In univariate analysis, variables at the diagnosis of NARDS that were considered to have a univariable association with mortality included gestational age, birth weight, age at admission, 5-min Apgar score, OI, lactate at admission, PROM, pneumonia, aspiration of blood, and perinatal asphyxia, with a $p$ value of less than 0.2 (Table 4). Furthermore, in multivariate analysis, variables at diagnosis of NARDS that retained an independent association with mortality included birth weight and OI. The factors associated with higher mortality were lower birth weight and higher OI (Table 5). 
Fig. 1 Flowchart of study enrollment

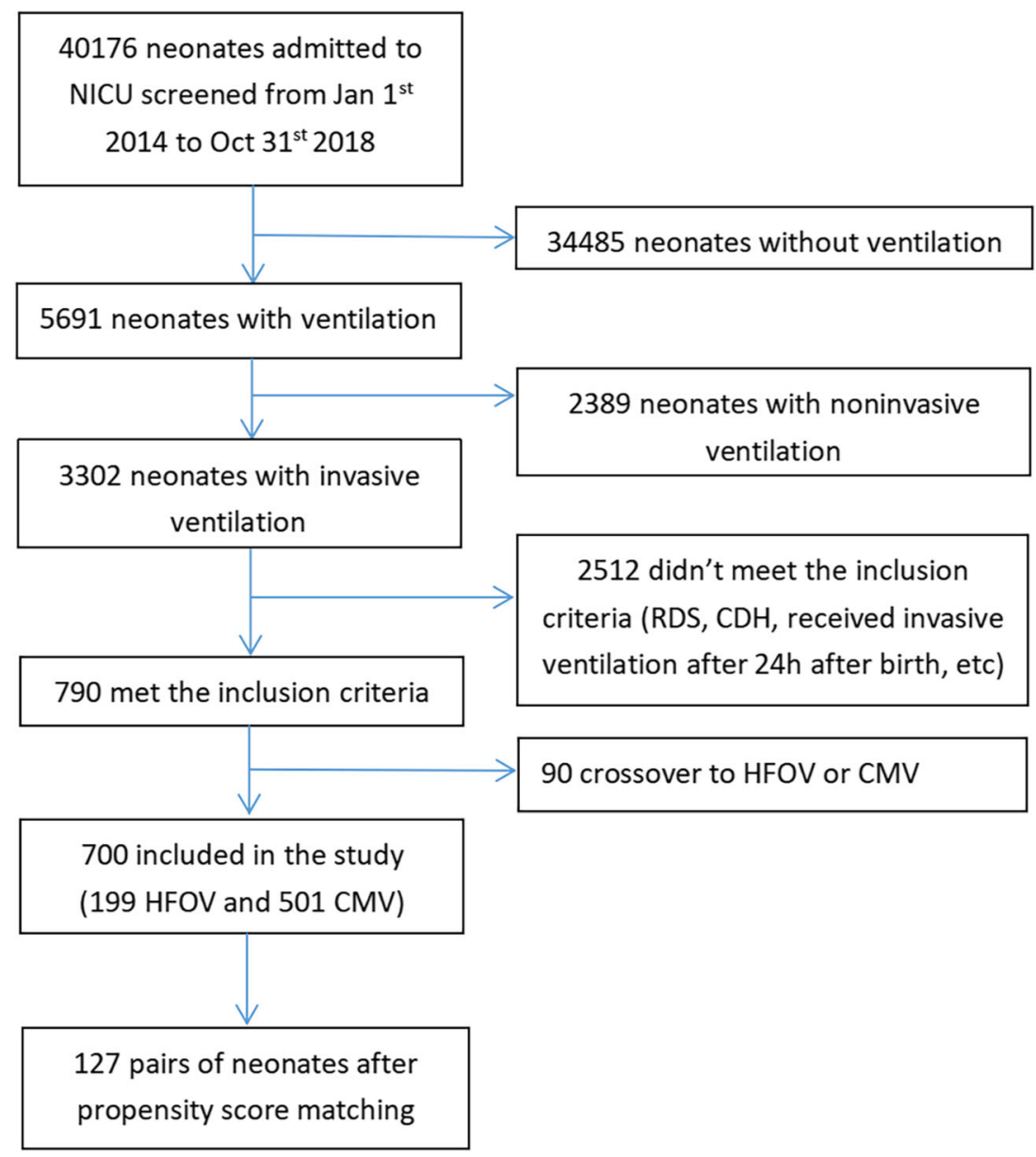

\section{Discussion}

Our study is the first to compare the mortality, incidence of BPD, and other complications between neonates with NARDS who received either CMV or HFOV. Our data suggest that there were no significant differences in mortality or the incidence of BPD between the CMV and HFOV groups.

PARDS occurred in approximately $6 \%$ of all mechanically ventilated children in pediatric intensive care units (PICUs) internationally [20], while in our study, NARDS occurred in approximately $12 \%(700 / 5691)$ of all mechanically ventilated infants in the NICU. The relatively higher incidence may be associated with unique triggers for respiratory failure (e.g., MAS, perinatal asphyxia) during the neonatal period that might differ from pediatric ARDS and variations in specific aspects of developmental lung biology and maturation and neonatal immune status [1]. In our study, the mortality of neonates with NARDS before matching was $18.5 \%$, and the mortality of neonates with NARDS was $25.2 \%$ after matching. However, data on the mortality of neonates with NARDS are lacking, and more studies reporting on the mortality of neonates with NARDS are needed. In this study, severe NARDS $(\mathrm{OI} \geq 16)$ was associated with higher mortality than moderate NARDS $(8 \leq \mathrm{OI}<16)$. In the Montreux definition, OI is recommended to determine hypoxemia severity [1], and hypoxemia severity is closely associated with mortality. A meta-analysis comparing HFOV and CMV revealed that there is no difference in mortality for acute pulmonary dysfunction in preterm infants. Likewise, in our study, no significant difference was observed in mortality between the CMV and HFOV groups after matching.

In our study, after matching, the incidence of BPD was $16.5 \%$ and $22.0 \%$ in the CMV and HFOV groups, respectively. Although BPD is mostly associated with premature birth, it can also occur in infants born at late preterm or term infants who need aggressive ventilator therapy for severe acute lung disease and in infants with risk factors for BPD, including infection, maternal hypertension or preeclampsia, patent ductus arteriosus (PDA) [21], and antenatal corticosteroid rate. In our study, the median gestational ages of neonates after matching were 34.86 weeks in the CMV group and 34.86 weeks in the HFOV group. The reasons for the relatively high rate of BPD might be that all the neonates enrolled in our study received invasive ventilation; among them, the incidence of early-onset sepsis was high, with rates of $34.6 \%$ in the CMV group and $33.1 \%$ in the HFOV group. However, the 
Table 1 Baseline characteristics of neonates in CMV and HFOV groups

\begin{tabular}{|c|c|c|c|c|c|c|}
\hline & \multicolumn{3}{|l|}{ Before matching } & \multicolumn{3}{|l|}{ After matching } \\
\hline & $\operatorname{CMV}(n=501)$ & HFOV $(n=199)$ & $p$ value & $\operatorname{CMV}(n=127)$ & $\operatorname{HFOV}(n=127)$ & $p$ value \\
\hline Gestational age, weeks & $34.0(31.3,37.8)$ & $35.4(31.1,38.7)$ & 0.157 & $34.86(31.71,38.71)$ & $34.86(31.00,38.71)$ & 0.615 \\
\hline Gender (male), no. (\%) & $294(58.7)$ & $133(66.8)$ & 0.046 & $41(43.2)$ & $86(54.1)$ & 0.092 \\
\hline Birth weight, $g$ & $2130(1505,2960)$ & $2300(1550,3100)$ & 0.071 & $2200(1520,3000)$ & $2310(1380,3050)$ & 0.888 \\
\hline Age at admission, $\mathrm{h}$ & $2.4(1.67,5.54)$ & $3.25(1.7,7.7)$ & 0.024 & $2.78(1.67,8.00)$ & $3(1.71,7.35)$ & 0.954 \\
\hline Age at NARDS diagnosis, $\mathrm{h}$ & $34.49(27.77,40.94)$ & $34.10(28.83,42.61)$ & 0.708 & $34.56(27.15,42.40)$ & $33.71(28.19,41.20)$ & 0.891 \\
\hline PROM (yes), no. (\%) & $147(29.3)$ & $60(30.2)$ & 0.832 & $36(28.3)$ & $36(28.3)$ & 1.000 \\
\hline Prenatal glucocorticoid (yes), no. (\%) & $136(27.1)$ & $38(19.1)$ & 0.026 & $22(17.3)$ & $23(18.1)$ & 0.869 \\
\hline Postnatal glucocorticoid (yes), no. (\%) & $6(1.19)$ & $10(5.02)$ & 0.002 & $2(1.57)$ & $6(4.72)$ & 0.281 \\
\hline 5' Apgar score & $8.43(7.17,9.45)$ & $8.67(7.58,9.62)$ & 0.026 & $8.56(7.38,9.53)$ & $8.73(7.55,9.67)$ & 0.347 \\
\hline $\mathrm{OI}$ & $10.4(8.3,15.1)$ & $16.9(12.5,24)$ & 0.000 & $15.60(10.40,20.00)$ & $16.00(11.10,20.00)$ & 0.773 \\
\hline Lactate at admission, $\mathrm{mmol} / \mathrm{L}$ & $3.6(2.4,5.4)$ & $3.7(2.5,5.6)$ & 0.630 & $3.933(2.57,5.6)$ & $3.963(2.493,5.483)$ & 0.985 \\
\hline
\end{tabular}

Data are presented as median (IQR), or number (\%)

$C M V$, conventional mechanical ventilation; $H F O V$, high-frequency oscillatory ventilation; $I Q R$, interquartile range; $M A S$, meconium aspiration syndrome; NARDS, neonatal acute respiratory distress syndrome; OI, oxygenation index; PROM, premature rupture of membranes

administration rate of prenatal glucocorticoids was low, with rates of $17.3 \%$ in the CMV group and $18.1 \%$ in the HFOV group.

The effects of HFOV or CMV on neurological outcomes are controversial. Some RCTs reported similar brain injury in neonates who received HFOV or CMV [22]. Cools et al. [5] reported that although increased risks of severe grade IVH and periventricular leukomalacia (PVL) were found in some studies, the overall meta-analysis revealed no significant differences in those effects between the HFOV and CMV groups. In our study, the incidence of IVH was higher in the CMV group than in the HFOV group. However, we did not show a long-term neurodevelopmental outcome in our study, and a longterm follow-up of neurodevelopmental outcomes is necessary. In our study, there were no significant differences in the incidence of air leakage, ROP, NEC, duration of invasive ventilation, or duration of hospitalization between the two groups, which was in agreement with the findings of previous studies reporting acute pulmonary dysfunction or respiratory distress syndrome (RDS) in preterm infants [5]. Our results also showed that there were significantly more VFDs in the CMV group than in the HFOV group. However, comprehensively considering the ability to reduce ventilator-dependent time and mortality, this result failed to show a benefit of HFOV in this respect.
Table 2 Triggers of NARDS in CMV and HFOV groups

\begin{tabular}{|c|c|c|c|c|c|c|}
\hline & \multicolumn{3}{|c|}{ Before matching } & \multicolumn{3}{|c|}{ After matching } \\
\hline & $\begin{array}{l}\text { CMV } \\
(n=501)\end{array}$ & $\begin{array}{l}\text { HFOV } \\
(n=199)\end{array}$ & $\begin{array}{l}p \\
\text { value }\end{array}$ & $\begin{array}{l}\text { CMV } \\
(n=127)\end{array}$ & $\begin{array}{l}\text { HFOV } \\
(n=127)\end{array}$ & $\begin{array}{l}p \\
\text { value }\end{array}$ \\
\hline \multicolumn{7}{|l|}{$\begin{array}{l}\text { Triggers (yes), no. } \\
(\%)\end{array}$} \\
\hline Sepsis & $163(32.5)$ & $70(35.2)$ & 0.504 & $44(34.6)$ & $42(33.1)$ & 0.791 \\
\hline $\begin{array}{l}\text { Pulmonary } \\
\text { hemorrhage }\end{array}$ & $139(27.7)$ & 77 (38.6) & 0.005 & $46(36.2)$ & $44(34.6)$ & 0.793 \\
\hline MAS & $15(2.9)$ & $11(5.5)$ & 0.110 & $8(6.3)$ & $7(5.5)$ & 0.790 \\
\hline Pneumonia & $115(22.9$ & $26(13.0)$ & 0.003 & $22(17.3)$ & $23(18.1)$ & 0.869 \\
\hline Aspiration of blood & $37(7.4)$ & $9(4.5)$ & 0.168 & $5(3.9)$ & $6(4.7)$ & 0.758 \\
\hline Perinatal asphyxia & $32(6.4)$ & $6(3.0)$ & 0.076 & $4(3.1)$ & $6(4.7)$ & 0.519 \\
\hline
\end{tabular}

Data are presented as number (\%)

$C M V$, conventional mechanical ventilation; $H F O V$, high-frequency oscillatory ventilation; $M A S$, meconium aspiration syndrome; NARDS, neonatal acute respiratory distress syndrome 
Table 3 Primary and secondary outcomes of neonates in CMV and HFOV groups after propensity score matching

\begin{tabular}{llll}
\hline & CMV $(n=127)$ & HFOV $(n=127)$ & $p$ value \\
\hline $\begin{array}{l}\text { Primary outcomes } \\
\text { Death (yes), no. (\%) }\end{array}$ & & $32(25.2)$ & 1.000 \\
BPD (yes), no. (\%) & $21(25.2)$ & $28(22.0)$ & 0.266 \\
Secondary outcomes & & $5(3.9)$ & 0.020 \\
IVH $\geq$ 3rd (yes), no. (\%) & $15(11.8)$ & $2(1.6)$ & 1.000 \\
ROP $\geq$ 2nd (yes), no. (\%) & $1(0.8)$ & $0(0.0)$ & 0.498 \\
NEC $\geq$ 2nd (yes), no. (\%) & $2(1.6)$ & $7(5.5)$ & 0.334 \\
Air leak (yes), no. (\%) & $3(2.4)$ & $79(62.2)$ & 0.795 \\
Surfactant treatment (yes), no. (\%) & $81(63.8)$ & $5(3.93)$ & 0.758 \\
PDA treatment (yes), no. (\%) & $6(4.72)$ & $149.47(63.69,325.03)$ & 0.060 \\
Duration of invasive ventilation, h & $114.54(62.05,182.85)$ & $15.226(0.000,22.291)$ & 0.010 \\
Ventilation free days, days & $20.967(0.000,24.354)$ & $17.83(5.50,33.50)$ & 0.813 \\
Duration of hospitalization, days & $17.91(9.13,29.63)$ & & \\
\hline
\end{tabular}

Data are presented as median (IQR), or number (\%)

$B P D$, bronchopulmonary dysplasia; $C M V$, conventional mechanical ventilation; $H F O V$, high-frequency oscillatory ventilation; $I V H$, intraventricular hemorrhage; $I Q R$, interquartile range; $N E C$, necrotizing enterocolitis; $R O P$, retinopathy of prematurity
There were no differences in the triggers of NARDS between the two groups after matching. In this study, the main triggers were sepsis and pulmonary hemorrhage. The rates of sepsis were $34.6 \%$ in the CMV group and $33.1 \%$ in the HFOV

Table 4 Univariate logistic regression analysis for mortality of neonates at NARDS diagnosis

\begin{tabular}{llll}
\hline & OR & $95 \%$ CI & $p$ value \\
\hline Gestational age, weeks & 0.865 & $0.822-0.910$ & $<0.001$ \\
Gender (male) & 0.913 & $0.619-1.347$ & 0.647 \\
Birth weight, g & 0.999 & $0.999-1.000$ & $<0.001$ \\
Age at admission, hours & 0.959 & $0.914-1.005$ & 0.081 \\
Age at NARDS diagnosis, hours & 1.007 & $0.987-1.027$ & 0.478 \\
PROM & 1.644 & $1.104-2.448$ & 0.014 \\
Prenatal glucocorticoid & 0.967 & $0.616-1.518$ & 0.883 \\
Postnatal glucocorticoid & 0.000 & 0.000 & 0.998 \\
5' Apgar score & 0.775 & $0.706-0.850$ & $<0.001$ \\
OI & 1.106 & $1.708-1.134$ & $<0.001$ \\
Lactate at admission & 1.9 .03 & $1.037-1.153$ & $<0.001$ \\
Sepsis & 0.831 & $0.549-1.256$ & 0.379 \\
Pulmonary hemorrhage & 1.235 & $0.825-1.849$ & 0.304 \\
MAS & 0.791 & $0.265-2.335$ & 0.671 \\
Pneumonia & 0.541 & $0.313-0.935$ & 0.028 \\
Aspiration of blood & 0.399 & $0.141-1.133$ & 0.085 \\
Perinatal asphyxia & 6.267 & $3.202-12.267$ & $<0.001$ \\
\hline
\end{tabular}

$C I$, confidential interval; $M A S$, meconium aspiration syndrome; NARDS, neonatal acute respiratory distress syndrome; $O R$, odds ratio; $O I$, oxygenation index; $P R O M$, premature rupture of membranes; $P D A$, patent ductus arteriosus group after matching. Randolph et al. [23] reported that the most common trigger was infection in children with ARDS. Goh et al. [24] reported that the rate of sepsis in children's ARDS triggers was $43 \%$, while Dahlem et al. [25] reported a rate of $34 \%$. The reported incidence of neonatal sepsis varies from 7.1 to 38 per 1000 live births in Asia [26, 27]. By comparison, rates reported in the USA and Australasia range from 1.5 to 3.5 per 1000 for early-onset sepsis [28]. This reminds us that although neonatal perinatal ARDS has its own unique trigger factors, such as MAS and asphyxia, similar to pediatric ARDS, sepsis is still an important trigger factor, especially in Asia. More attention should be paid to sepsis by clinical neonatal physicians. In addition, the rates of pulmonary hemorrhage were $36.2 \%$ in the CMV group and $34.6 \%$ in the HFOV group after matching. The exact pathogenesis of pulmonary

Table 5 Multivariate logistic regression analysis for mortality of neonates at NARDS diagnosis

\begin{tabular}{llll}
\hline & OR & $95 \%$ CI & $p$ value \\
\hline Gestational age, weeks & 0.865 & $0.822-0.910$ & $<0.001$ \\
Birth weight, g & 0.999 & $0.999-1.000$ & 0.038 \\
PROM & 1.374 & $0.857-2.205$ & 0.187 \\
5' Apgar score & 0.889 & $0.761-1.039$ & 0.138 \\
OI & 1.119 & $1.087-1.151$ & $<0.001$ \\
Lactate at admission & 1.069 & $0.997-1.145$ & 0.059 \\
Pneumonia & 0.839 & $0.450-1.564$ & 0.580 \\
Perinatal asphyxia & 2.705 & $0.902-8.105$ & 0.076 \\
\hline
\end{tabular}

$C I$, confidential interval; NARDS, neonatal acute respiratory distress syndrome; $O R$, odds ratio; $O I$, oxygenation index 
hemorrhage remains unknown; some studies have described that it is associated with hypoxemia, sepsis, and PDA [29]. Further exploration is still needed to define the triggers of NARDS.

Multivariate analysis found that birth weight and OI trend were the most significant factors associated with mortality. An RCT on ARDS in adults conducted by Derdark et al. [30] also reported that the OI trend was the most significant posttreatment predictor of survival irrespective of the assigned ventilator. In a recent randomized trial for pediatric ARDS, the severity of hypoxia was measured by the OI, and the average mortality in children with an $\mathrm{OI} \geq 13$ at study entry was 36 vs $20 \%$ in those with an $\mathrm{OI} \leq 12$ [23]. In this study, the mortality of patients with severe NARDS $(\mathrm{OI} \geq 16)$ was $40.47 \%$, which was higher than that of patients with moderate NARDS $(8 \leq \mathrm{OI}<16)$, which was $10.23 \%$ after matching.

Many factors, related to both the intervention itself and the individuals, could interact in complex ways. The disease severity, clinical management, ventilator properties, and clinical interventions warrant further exploration of outcomes with a multivariate modeling approach. Considering the patient's clinical features, physiological status, and response to ventilatory support to determine how to optimally ventilate the patient is of great importance [31]. A study showed that the use of a reduced tidal volume and avoidance of high airway pressures were associated with improved mortality when compared with a conventional ventilatory approach [32]. Adequate use of either mode of ventilation is crucial for neonatologists, and the importance of applying an optimal lung recruitment strategy during HFOV and monitoring and controlling tidal volume with the VG during conventional ventilation should be considered [32,33]. A new ventilator strategy, HFOV combined with VG, has also been demonstrated to be a potential strategy to prevent lung injury [34].

There are several limitations in this study, including the following: (1) the relatively small number of patients; (2) this was a single-center study in Chinese newborns; (3) it was a retrospective paper, and Chan et al. [35] concluded that many questions remained unanswered, and HFOV should be compared to CMV in a large randomized, controlled trial; (4) propensity score matching (PSM) can balance more variables at the same time, which can only be limited to the known confounding variables, and some unknown confounding variables may still have an impact on the final result; (5) there was a lack of assessment of long-term neurodevelopmental outcomes; and (6) patients enrolled in our study who received invasive ventilation and patients with NARDS who were undergoing noninvasive ventilation were excluded.

According to the Montreux criteria, early-onset sepsis and NARDS perinatal triggers are defined by those occurring in the first $72 \mathrm{~h}$ of life. In this study, we aimed to explore whether HFOV was superior to CMV in decreasing mortality and the incidence of BPD in infants with NARDS. To reduce various types of heterogeneity and confounding factors, we targeted neonates with moderate-to-severe NARDS that occurred in the first $24 \mathrm{~h}$ of life. Late-onset sepsis was defined as a positive result on one or more blood cultures obtained after 72h [36]. The onset time of NEC usually occurs on the 3rd or 4th day of life in term neonates, and the onset time may be delayed for up to three or 4 weeks in preterm neonates [37]. NARDS triggered by late-onset sepsis or NEC may be ventilated after $24 \mathrm{~h}$. Therefore, those with NARDS triggered by late-onset sepsis or NEC were excluded. Thus, our study results could not apply to NARDS triggered by late-onset sepsis or NEC and other types of NARDS. Taken these limitations into account, this retrospective study may have some implications for clinical practice and future research on HFOV vs CMV in infants with perinatal-onset NARDS.

In summary, in this retrospective study, our results showed that HFOV was associated with reduced IVH in neonates with moderate-to-severe perinatal-onset NARDS compared with CMV. However, VFDs in the CMV group were significantly higher than those in the HFOV group and did not appear to be superior to CMV for decreasing mortality and the incidence of BPD in neonates with moderate-to-severe perinatal-onset NARDS.

Authors' contributions All authors contributed to the study conception and design. Material preparation, data collection, and analysis were performed by Long Chen, Jing Xiong, and Shuqin Xie. The first draft of the manuscript was written by Kaizhen Liu. The manuscript was revised by Yuan Shi and all authors commented on previous versions of the manuscript. All authors read and approved the final manuscript.

Funding This study was funded by the National Clinical Research Center of China and Clinical Medical Study Program of Children's Hospital of Chongqing Medical University (NCRC-2019-GP-13).

Data availability Yuan Shi is the guarantor of this work and, as such, had full access to all the data in the study, and takes responsibility for the integrity of the data and the accuracy of the data analysis. Data will be made available upon request.

\section{Declarations}

Ethics approval and consent to participate This study was approved by the Institutional Review Board, Children's hospital of Chongqing Medical University of China. Not applicable

Consent for publication Not applicable

Conflict of interest The authors declare no competing interest.

\section{References}

1. De Luca D, van Kaam AH, Tingay DG et al (2017) The Montreux definition of neonatal ARDS: biological and clinical background behind the description of a new entity. Lancet Respir Med 5(8): 657-666 
2. Lee SH, Choi CW, Oh YK, Kim BI (2016) Atypical acute respiratory disorder in late preterm and term newborn infants. J Matern Fetal Neonatal Med 29(9):1430-1434

3. Kinsella JP, Clark RH (1993) High-frequency oscillatory ventilation in pediatric critical care. Crit Care Med 21(2):174-175

4. Guo YX, Wang ZN, Li YT, Pan L, Yang LF, Hu Y, Sun YY, Cai LM, Chen Z (2016) High-frequency oscillatory ventilation is an effective treatment for severe pediatric acute respiratory distress syndrome with refractory hypoxemia. Ther Clin Risk Manag 12: $1563-1571$

5. Cools F, Offringa M, Askie LM (2015) Elective high frequency oscillatory ventilation versus conventional ventilation for acute pulmonary dysfunction in preterm infants. Cochrane Database Syst Rev 3:CD000104

6. Emeriaud JABCCECDMDD. Mechanical ventilation. 149-274

7. Iqbal Q, Younus MM, Ahmed A et al (2015) Neonatal mechanical ventilation: indications and outcome. Indian J Crit Care Med 19(9): 523-527

8. Bollen C, Peter C. (2015) Pediatric\& neonatal mechanical ventilation. In: P.C. Rimensberger (ed.). 559-575 .

9. Dani C, Bertini G, Pezzati M, Cecchi A, Caviglioli C, Rubaltelli FF (2004) Early extubation and nasal continuous positive airway pressure after surfactant treatment for respiratory distress syndrome among preterm infants $<30$ weeks' gestation. Pediatrics. 113(6): e560-e563

10. Dargaville PA, Copnell B (2006) Australian and New Zealand Neonatal Network. The epidemiology of meconium aspiration syndrome: incidence, risk factors, therapies, and outcome. Pediatrics. 117(5):1712-1721

11. Jobe AH, Bancalari E (2001) Bronchopulmonary dysplasia. Am J Respir Crit Care Med 163(7):1723-1729

12. Vander JF, McNamara JA, Tasman W, Brown GC (2005) Revised indications for early treatment of retinopathy of prematurity. Arch Ophthalmol 123(3):406-407 discussion 409-10

13. Sharma R, Hudak ML (2013) A clinical perspective of necrotizing enterocolitis: past, present, and future. Clin Perinatol 40(1):27-51

14. Radic JA, Vincer M, McNeely PD (2015) Outcomes of intraventricular hemorrhage and posthemorrhagic hydrocephalus in a population-based cohort of very preterm infants born to residents of Nova Scotia from 1993 to 2010. J Neurosurg Pediatr 15(6):580 588

15. Schoenfeld DA, Bernard GR, Network ARDS (2002) Statistical evaluation of ventilator-free days as an efficacy measure in clinical trials of treatments for acute respiratory distress syndrome. Crit Care Med 30(8):1772-1777

16. Flori HR, Glidden DV, Rutherford GW, Matthay MA (2005) Pediatric acute lung injury: prospective evaluation of risk factors associated with mortality. Am J Respir Crit Care Med 171(9):9951001

17. Herting E, Möller O, Schiffmann JH, Robertson B (2002) Surfactant improves oxygenation in infants and children with pneumonia and acute respiratory distress syndrome. Acta Paediatr 91(11):1174-1178

18. ARDS Definition Task Force, Ranieri VM, Rubenfeld GD et al (2012) Acute respiratory distress syndrome: the Berlin Definition. JAMA. 307(23):2526-2533

19. Austin PC (2009) The relative ability of different propensity score methods to balance measured covariates between treated and untreated subjects in observational studies. Med Decis Mak 29(6): 661-677

20. Khemani RG, Smith L, Lopez-Fernandez YM, Kwok J, Morzov R, Klein MJ, Yehya N, Willson D, Kneyber MCJ, Lillie J, Fernandez A, Newth CJL, Jouvet P, Thomas NJ, Abaleke E, Ackerman KG, Acuña C, Adu-Darko M, Affolter JT, Agbeko R, al Amoudi A, Alahmadti A, Aldairi N, Alibrahim O, Allen K, Allen C, al-Subu A, Althabe M, Alvear J, Anil AB, Anthony H, Aramburo A, Arjona
Villanueva D, Ashtari N, Ávila Vera A, Baines P, Bales M, Barr S, Barry D, Baudin F, Beca J, Belfield H, Beltramo F, Benken L, Bhalla A, Blom A, Botta P, Bourgoin P, Brezmes M, Briassoulis G, Bridier A, Brierley J, Brio Sanagustin S, Broden E, Butt W, Bysani K, Camilo C, Camporesi A, Campos-Miño S, Can FK, Capocasa P, Caro I D, Carroll C, Castellani P, Castillo AE, Chen Y, Chima RS, Chiusolo F, Cinquegrani K, Coates B, CoronadoMunoz A, Cortéz A, Cruces Romero P, Cullimore M, Cvijanovich N, Dahmer MK, Deep A, Delzoppo C, di Nardo M, Díaz F, Dijkstra S, Dockery WK, Dominguez TE, Dumitrascu M, Dursun O, Dwarakanathan B, Elghuwael I, Emeriaud G, Erickson S, Español SF, Estil JB, Feather C, Feinstein Y, Fernández A, Ferreyra M, Flori H, Fortini YV, Fortune PM, French ME, Gaboli M, Gale H, García Casas P, García González M, Gautam R, Gedeit R, Genuini M, Gertz S, Giampieri M, Gil Escobar C, Giuliano Jr JS, Godoy Mundaca L, Goni Orayen C, Gonzalez Gomez JM, Govantes B, Guichoux J, Guzman Rivera GA, Haileselassie B, Han YY, Harrell A, Hartmann S, Hazwani T, Hefley G, Henderson G, Hsing DD, Hughes-Schalk A, Hume J, Ilia S, Inwald D, Iolster T, Izquierdo LM, Jafari-Namin S, Jaimon N, Jarillo Quijada AE, Jarvis JD, Jayachandran C, Jennings C, Jeyapalan AS, Jimenez Rivera NJ, Jones D, Jouvet P, Kasch M, Keary J', Kelley C, Kessel A, Khemani R, Kida Y, King C, Kneyber M, Kniola A, Krallman K, Kubis S, Kustka L, Kwok J, Kyo M, Landry LM, Latifi S, LawtonWoodhall A, Lillie J, Lin JC, Llorente de la Fuente AM, Lopez Alarcón YP, López Fernández Y, Lopez-Herce J, Lum LCS, Macrae D, Maddux AB, Madurga Revilla P, Mahapatra S, Maria M, Martínez L, Martinez de Azagra A, Martínez León AF, Mazzillo Vega L, McCorkell J, McIntyre K, Medina T, Medina A, Mellish C, Mendizabal M, Merritt C, Mildner R, Milesi C, Modesto I Alapont V, Monjes C, Monjure T, Montes MJ, Morales Martinez A, Morgan R, Morzov R, Mourani PM, Murkowski K, Murphy M, Napolitano N, Nerheim D, Nett ST, Newth C, Nofziger R, Nunez MJ, Ohshimo S, Onate Vergara E, Ongun EA, Orqueda D, Oruganti S, Pagowska-Klimek I, Palanca Arias D, Pappachan J, Pardo Carrero R, Parker MM, Parrilla J, Patankar N, Pávez Madrid P, Payen V, Paziencia F, Pedraza C, Perez Lozano G, Pilar Orive J, Piñeres Olave BE, Pintimalla A, Pinto N, Plunkett A, Pon S, Pons Odena M, Poterala R, Qiao H, Quiñonez Lopez D, Ralston K, Ramirez Cortez G, Ratiu A, Rea M, Reyes Dominguez S, Rodgers C, Rodriguez Campoy P, Ronan L, Rosemary D, Rowan C, Sadasivam K, Sanchez Diaz JI, Sanders R, Santanelli J, Sapru A, Schneider J, Sforza J, Shea S, Shein SL, Sherring C, Sheward V, Shime N, Shukla A, Siaba Serrate A, Sierra Y, Sikora L, Silvestre C, Singleton M, Sloniewsky D, Smith R, Smith L, Song H, Sousa Moniz M, Spaeder M, Spear D, Spinella P, Starck J, Stoneman E, Su F, Subramanian G, Sullivan E, Sundararajan S, Sweberg T, Sykes K, Tabata Y, Tai CW, Tala J, Tang SF, Tantalean J, Taylor R, Thomas N, Tibby S, Tieves KS, Torero L, Torres SF, Totapally B, Travert B, Truemper E, Turón G, Typpo K, Valle JR, Vargas G SI, Vasquez Hoyos P, Vasquez Miranda D, Vavrina M, Vidal NÁ, Virk M, Walsh L, Wegner Araya A, Weitz J, Wellisch L, Wellman P, Willson D, Woods K, Yehya N, Yerovi R, Yunger T, Zuluaga Orrego C, Zurek J (2019) Paediatric acute respiratory distress syndrome incidence and epidemiology (PARDIE): an international, observational study. Lancet Respir Med 7(2):115-128

21. Taglauer E, Abman SH, Keller RL (2018) Recent advances in antenatal factors predisposing to bronchopulmonary dysplasia. Semin Perinatol 42(7):413-424

22. Marlow N, Greenough A, Peacock JL, Marston L, Limb ES, Johnson AH, Calvert SA (2006) Randomised trial of high frequency oscillatory ventilation or conventional ventilation in babies of gestational age 28 weeks or less: respiratory and neurological outcomes at 2 years. Arch Dis Child Fetal Neonatal Ed 91(5):F320F326 
23. Randolph AG (2009) Management of acute lung injury and acute respiratory distress syndrome in children. Crit Care Med 37(8): 2448-2454

24. Goh AY, Chan PW, Lum LC, Roziah M (1998) Incidence of acute respiratory distress syndrome: a comparison of two definitions. Arch Dis Child 79(3):256-259

25. Dahlem P, van Aalderen WM, Bos AP (2007) Pediatric acute lung injury. Paediatr Respir Rev 8(4):348-362

26. Lim NL, Wong YH, Boo NY, Kasim MS, Chor CY (1995) Bacteraemic infections in a neonatal intensive care unit-a ninemonth survey. Med J Malaysia 50(1):59-63

27. Tallur SS, Kasturi AV, Nadgir SD, Krishna BV (2000) Clinicobacteriological study of neonatal septicemia in Hubli. Indian $\mathrm{J}$ Pediatr 67(3):169-174

28. Schuchat A, Zywicki SS, Dinsmoor MJ, Mercer B, Romaguera J, O'Sullivan MJ, Patel D, Peters MT, Stoll B, Levine OS, the Prevention of Early-onset Neonatal Sepsis (PENS) Study Group (2000) Risk factors and opportunities for prevention of earlyonset neonatal sepsis: a multicenter case-control study. Pediatrics. 105(1 Pt 1):21-26

29. Riad Abou Zahr AA, Marron-Corwin M (2012) Neonatal pulmonary hemorrhage. Neoreviews 13:e302-e306

30. Derdak S, Mehta S, Stewart TE, Smith T, Rogers M, Buchman TG, Carlin B, Lowson S, Granton J, the Multicenter Oscillatory Ventila (2002) High-frequency oscillatory ventilation for acute respiratory distress syndrome in adults: a randomized, controlled trial. Am J Respir Crit Care Med 166(6):801-808

31. Sklar MC, Patel BK, Beitler JR, Piraino T, Goligher EC (2019) Optimal ventilator strategies in acute respiratory distress syndrome. Semin Respir Crit Care Med 40(1):81-93
32. Acute Respiratory Distress Syndrome Network, Brower RG, Matthay MA et al (2000) Ventilation with lower tidal volumes as compared with traditional tidal volumes for acute lung injury and the acute respiratory distress syndrome. N Engl J Med 342(18): 1301-1308

33. De Jaegere A, van Veenendaal MB, Michiels A, van Kaam AH (2006) Lung recruitment using oxygenation during open lung high-frequency ventilation in preterm infants. Am J Respir Crit Care Med 174(6):639-645

34. Sánchez-Luna M, González-Pacheco N, Belik J, Santos M, Tendillo F (2018) New ventilator strategies: high-frequency oscillatory ventilation combined with volume guarantee. Am J Perinatol 35(6):545-548

35. Chan KP, Stewart TE (2005) Clinical use of high-frequency oscillatory ventilation in adult patients with acute respiratory distress syndrome. Crit Care Med 33(3 Suppl):S170-S174

36. Stoll BJ, Hansen N, Fanaroff AA, Wright LL, Carlo WA, Ehrenkranz RA, Lemons JA, Donovan EF, Stark AR, Tyson JE, Oh. W, Bauer CR, Korones SB, Shankaran S, Laptook AR, Stevenson DK, Papile LA, Poole WK (2002) Late-onset sepsis in very low birth weight neonates: the experience of the NICHD Neonatal Research Network. Pediatrics. 110(2 Pt 1):285-291

37. Shao X, Ye H, Qiu X (2011) Practical neonatology (4th edition). People's Medical Publishing House, pp 477-482

Publisher's note Springer Nature remains neutral with regard to jurisdictional claims in published maps and institutional affiliations. 